\title{
Suitability Assessment of Construction and Demolition Waste as a Highway Material
}

\author{
Afroja Sultana*1(D), Md. Mostafizur Rahman ${ }^{2}$ (D) \\ ${ }^{1}$ Lecturer, Prime University, Dhaka, Bangladesh \\ ${ }^{2}$ Graduate Student, Faridpur Engineering College, Bangladesh
}

\section{Keywords}

Construction,

Solid waste,

Construction and Demolition Waste,

Conventional Aggregate,

Road pavement.

\begin{abstract}
For Being a developing country urbanization is growing rapidly in Bangladesh and there has been a significant increase in the construction of roads. But due to lack of financial aid many of the roads are still unsealed. However, not only the utilization of Construction and Demolition Waste (CDW) in flexible pavement will be helpful for the reduction of road construction costs but also it will help to reduce environmental pollution which may be caused by disposing CDW in open area. The objective of this research is to utilize the CDW in base and sub base layers in the flexible pavement design to reduce the cost of road construction and environmental pollution. Proceeding by collecting CDW like brick from demolished building and conventional brick from kiln, a no of standard test conducted in laboratory namely Aggregate Impact Value, Crushing Value, Specific Gravity, Water Absorption and Loss Angeles Abrasion Test for three times. After analyzing the test results, we found that the average Aggregate Impact Value for CDW and Conventional Aggregate (CA) are respectively $29.52 \%$ and $23.87 \%$, Aggregate Crushing value for CDW and CA are respectively $28.10 \%$ and $22.88 \%$, Los Angeles Abrasion value for CDW and CA are respectively $31.47 \%$ and $28.52 \%$, specific gravity value for CDW and CA both is 1.75 , water absorption for CDW and CA are respectively $7.62 \%$ and $12.23 \%$. After analyzing the test results and comparing with the standard value, we figure out that the CDW are useful for using base and sub base layers in the flexible pavement.
\end{abstract}

\section{Introduction}

Sustainable construction and infrastructural management largely depend on the recycling and reuse of construction and demolition waste. Unfortunately, the amount of this waste is increasing every year beyond the satisfaction level [1]. In 2010, the total waste generated in European Union amounted to 2.51 billion tones [2]. The reuse of construction waste is highly essential from the viewpoint of Life Cycle Assessment (LCA) and effective recycling of construction resources [3]. Construction and demolition waste (CDW) are one of the heaviest and most voluminous waste streams generated all over the world. It accounts for approximately up to one-third of all waste generated all over the world and consists of numerous materials including concrete, bricks, tiles, reinforcement bar, wood, glass, metals, plastic, excavated soil etc. many of which can be recycled (Fig. 1). Construction and demolition wastes are generally produced from activities like the construction of buildings and civil engineering infrastructure, road planning and maintenance etc.

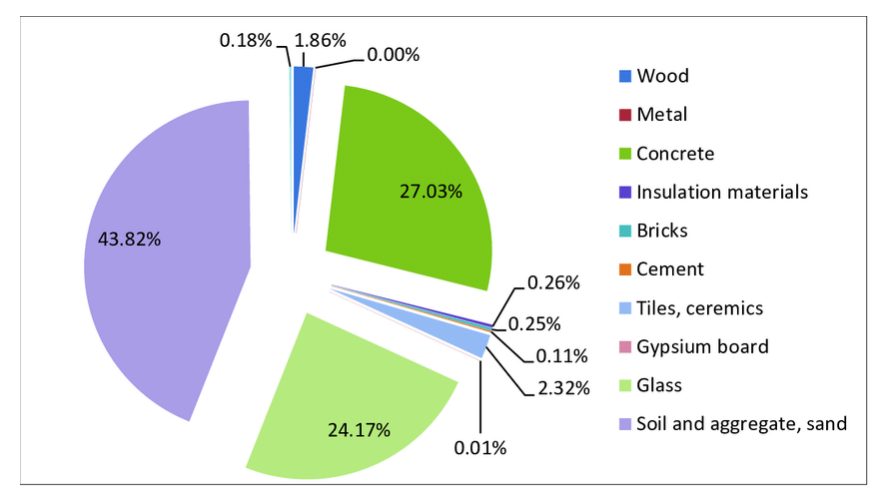

Figure 1. CDW composition [4]

The potentiality is so much high for recycling and consumption of CDW, because some of its components have a high resource value. In particular, there is a re-use market for aggregates which are actually derived from CDW waste in roads, drainage and many other construction projects. Technology for the separation and recovery of construction and demolition waste is well established, readily accessible and in general inexpensive. 
Roads are the pathway over which different varieties of vehicles, pedestrians and other traffic may pass conveniently. All road pavements usually fall into two broad categories: Flexible and Rigid Pavements. In rigid pavement, stress on pavements due to vehicular load is taken up by the slab action which are mainly constructed with Portland Cement Concrete (PCC). On the contrary flexible pavements are multi layered structures in which the stresses coming from the vehicular traffic are distributed and reduced such that they cannot exceed the stress sustaining capacity of the subgrade layer. The flexible pavements typically composed of layers which are surface course, base course, subbase and the subgrade by name. The effective service of flexible pavement is dependent on the load distributing capability of each of the component layers [7].

The core objectives of this study are to analyze the viability of Construction Demolition Waste (CDW) for improving the performance of base and sub base layers of flexible pavement road design and to minimize the use of conventional aggregate.

\section{Methodology}

Materials associated with this research are mainly construction and demolition waste and conventional brick for making conventional aggregate. The corresponding work sequence of this research is stated in the flow diagram as shown in Fig. 2.

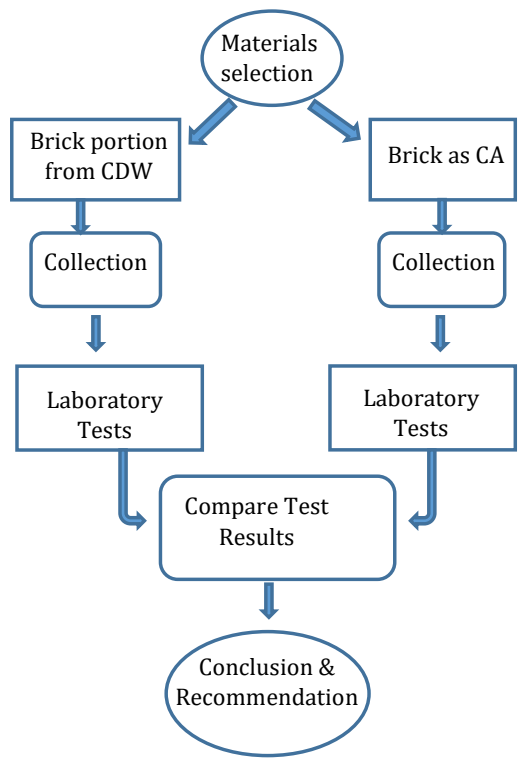

Figure 2. Research work flow diagram

The construction and demolished aggregates for recycling were obtained from an owner who demolished his own building to make a new building in Mirpur area, Dhaka, Bangladesh. Among them we received a lot of building waste materials along with concrete pieces, brick, timber, steel, tiles etc. After collecting all materials identification was made which materials can reusable and which materials can be recycled. Graphical representation of percentage of reusable and recyclable materials is shown in pie chart Fig. 3.

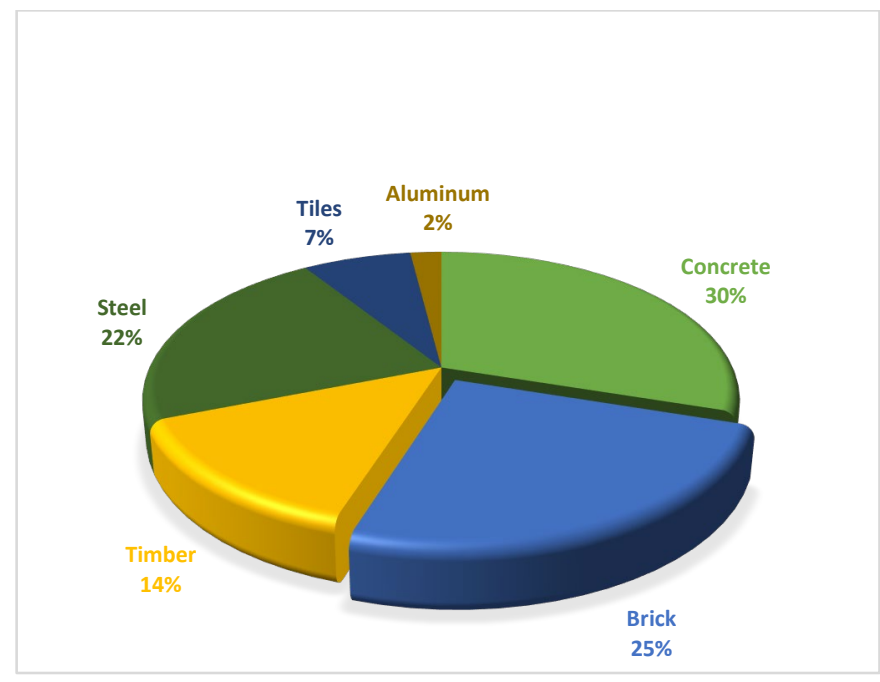

Figure 3. Reusable and recyclable materials (\%)

After that collected the conventional or original aggregate from manufacturing sources, laboratory tests like Aggregate Impact Value (AIV), Aggregate Crushing Value (ACV), Specific gravity, Water absorption and Los Angeles Abrasion test were conducted to check their properties and compared the properties of CDW aggregate with the conventional aggregate.

\subsection{Aggregate Impact Value test}

Impact Test on Aggregates is done to carry out to Determine the impact value of the road aggregates and to assess their suitability in road construction on the basis of impact value. Aggregate impact value measures the relative resistance of an aggregate sample against sudden or impact load. The test was carried out by filling a steel test mold with a sample of aggregate passing sieve size of $14 \mathrm{~mm}$ and retained on $10 \mathrm{~mm}$. The Aggregate Impact Value (AIV) was calculated as percentage of the weight of fines passing $2.36 \mathrm{~mm}$ sieve to the weight of the amount of material subjected to test after the test sample was subjected to 15 blows of standard impact load falling from height of $380 \mathrm{~mm}$ [8]. The result is summarized as shown in Table 1.

Table 1. Aggregate Impact Value for CDW and CA

\begin{tabular}{ccc}
\hline $\begin{array}{c}\text { Sample } \\
\text { No }\end{array}$ & $\begin{array}{c}\text { Construction and Demolition } \\
\text { waste (CDW) (\%) }\end{array}$ & $\begin{array}{c}\text { Conventional } \\
\text { Aggregate (CA) (\%) }\end{array}$ \\
\hline A1 & 30.02 & 23.67 \\
B1 & 28.7 & 24.7 \\
C1 & 29.67 & 22.34 \\
D1 & 31.7 & 23.33 \\
E1 & 29.34 & 21.9 \\
F1 & 30.08 & 25.6 \\
G1 & 29.9 & 25.86 \\
H1 & 26.75 & 23.56 \\
\hline Average & 29.52 & 23.87 \\
\hline
\end{tabular}




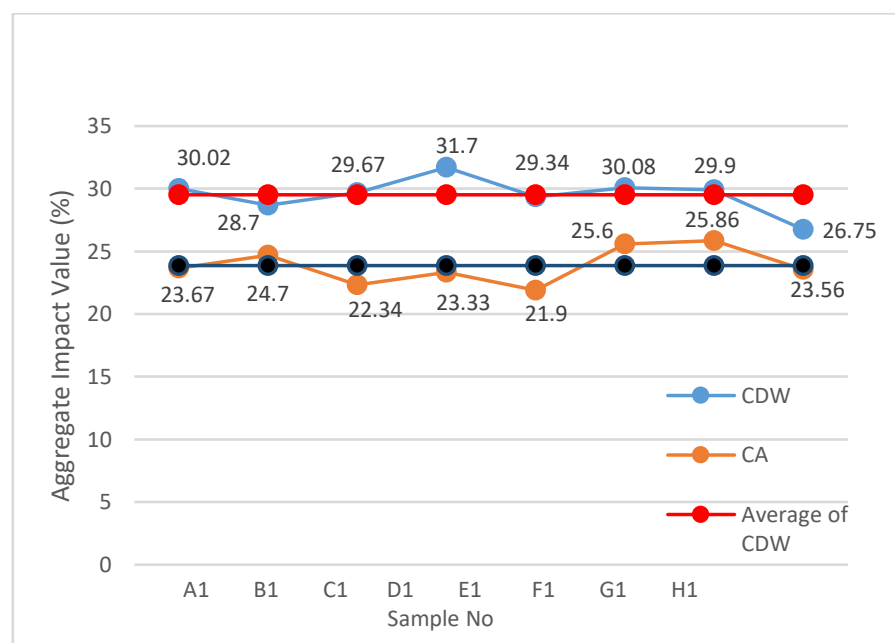

Figure 4. AIV test values for CDW and CA

From the graphical representation (Fig.4) it is easily appeared that the average AIV value of CDW is just $13.5 \%$ more than CA and the value is in the limit of $20-30 \%$ category of standard value (Table 2) and which is satisfactory for road surfacing. AIV up to $20 \%$ indicates strong aggregates and AIV up to $30 \%$ is found to be satisfactory for road surfacing [9]

Table 2. Aggregate strength based on their impact value [10]

\begin{tabular}{cc}
\hline Aggregate Impact Value & Classification \\
\hline$<20 \%$ & Exceptionally Strong \\
$10-20 \%$ & Strong \\
$20-30 \%$ & Satisfactory for road surfacing \\
$>35 \%$ & Weak for road surfacing \\
\hline
\end{tabular}

\subsection{Aggregate Crushing Value test}

Aggregate crushing value test on coarse aggregates gives a relative measure of the resistance of an aggregate crushing under gradually applied compressive load in a standard condition. It is a numerical index of the strength of the aggregate which are important for categories an aggregate. Coarse aggregate crushing value is actually the percentage by weight of the crushed material obtained when under standardized conditions test aggregates are subjected to a specified load. It mainly indicates its strength where lower crushing value is recommended for roads and pavements as it indicates a lower crushed fraction under load and would give a longer service life and a more economical performance. For this phenomenon, the aggregates used in roads and pavement construction must be strong enough to withstand crushing under roller and traffic activities. ACV was found to be a strong indicator for this property of concretes with strengths of $40 \mathrm{MPa}$ or less [11]. This test was conducted on aggregate which passing $12.5 \mathrm{~mm}$ and retained on a $10 \mathrm{~mm}$ sieve. Then the aggregate sample was filled in a cylindrical mold and a load of 40 tons applied through a plunger in a standard compression testing machine. The crushed aggregate sample which were finer than $2.36 \mathrm{~mm}$ was separated and expressed as a percentage of the original weight taken in the mold. The percentage of weight passed through the $2.36 \mathrm{~m}$ IS sieve is taken as Aggregate Crushing Value. There were 8 sets of test value of CDW and CA as stated in Table 3 .
Table 3. ACV test values for CDW and CA

\begin{tabular}{ccc}
\hline $\begin{array}{c}\text { Sample } \\
\text { No }\end{array}$ & $\begin{array}{c}\text { Construction and Demolition } \\
\text { waste (CDW) }\end{array}$ & $\begin{array}{c}\text { Conventional } \\
\text { Aggregate (CA) }\end{array}$ \\
\hline A2 & 27.88 & 22.63 \\
B2 & 28.3 & 23.56 \\
C2 & 28.6 & 23.43 \\
D2 & 28.98 & 23.36 \\
E2 & 29.02 & 22.45 \\
F2 & 28.01 & 23.17 \\
G2 & 27.46 & 22.56 \\
H2 & 26.55 & 21.88 \\
\hline Average & 28.1 & 22.88 \\
\hline
\end{tabular}

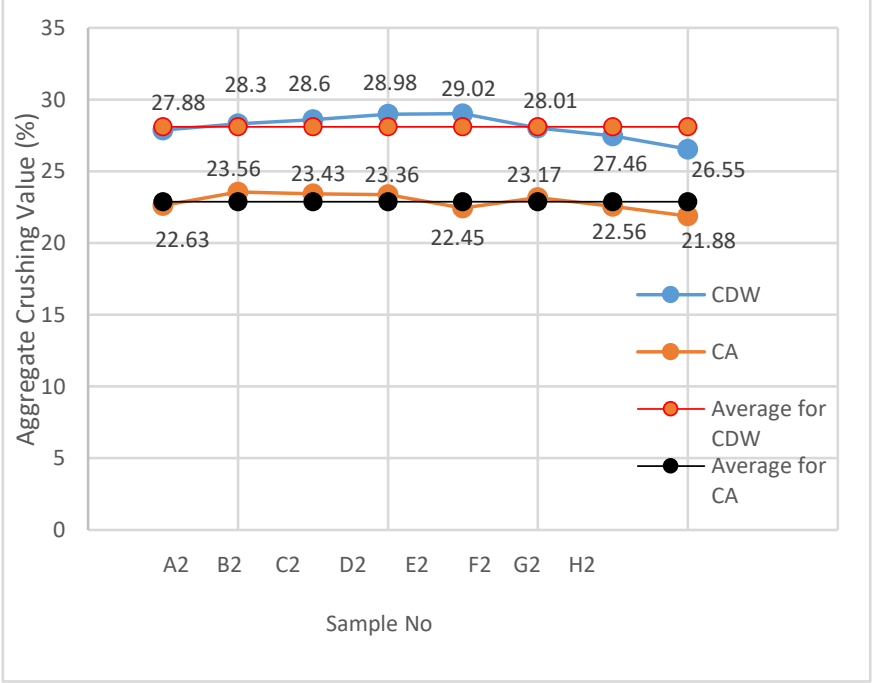

Figure 5. ACV test values for CDW and CA

According to IS-2386 Part IV (1963), an ACV value lower than $10 \%$ denotes a very strong aggregate and at the same time an ACV value more than $35 \%$ signifies a weak aggregate that should not be used in base/subbase pavement applications [12]. The results obtained in this study showed that ACV values for CDW is $28.1(\%)$ and for CA is $22.88(\%)$ which is much lower than $35 \%$.

\subsection{Los Angeles Abrasion test}

Los Angeles abrasion test on aggregates is the measure of aggregate toughness and abrasion resistance such as crushing, degradation and disintegration. The Los Angeles (L.A.) abrasion test is a common test method used to indicate aggregate toughness and abrasion characteristics, because aggregates must have to undergo substantial wear and tear throughout their life. In general, they need to be hard and tough enough to defend against crushing, degradation and disintegration from any associated activities including manufacturing, stockpiling, production, placing, compaction etc. The LA abrasion values are stated in the Table 4

Table 4. LA abrasion values for CDW and CA 


\begin{tabular}{ccc}
\hline $\begin{array}{c}\text { Sample } \\
\text { No }\end{array}$ & $\begin{array}{c}\text { Construction and } \\
\text { Demolition waste (CDW) }\end{array}$ & $\begin{array}{c}\text { Conventional Aggregate } \\
\text { (CA) }\end{array}$ \\
\hline A3 & 33.1 & 26.4 \\
B3 & 34.22 & 28.56 \\
C3 & 30.34 & 27.9 \\
D3 & 31.8 & 30.56 \\
E3 & 28.67 & 29.44 \\
F3 & 28.56 & 28.47 \\
G3 & 29.44 & 27.56 \\
H3 & 35.6 & 29.3 \\
\hline Average & 31.47 & 28.52 \\
\hline
\end{tabular}

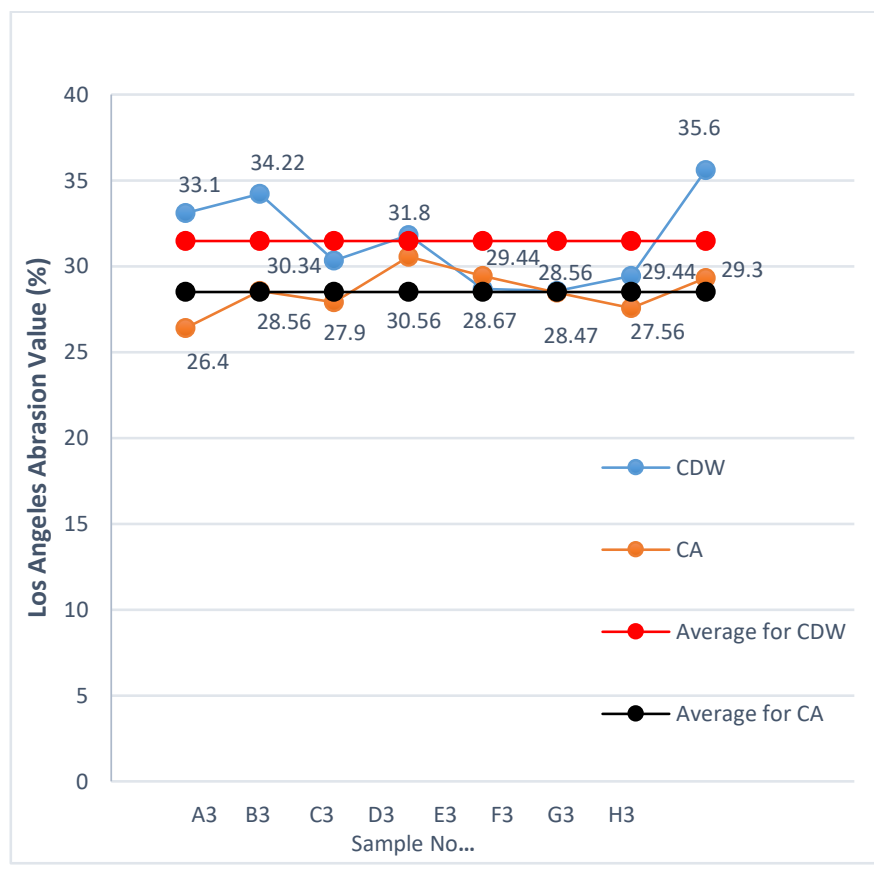

Figure 6. LA abrasion test values for CDW and CA

The requirements of LA value for aggregates are usually established by state or local agencies, the recommended allowable LA value is less than $35 \%$ [13]. The results obtained in this study is that average values for CDW is 31.47 which is $10.3 \%$ greater than CA but much lower than $35 \%$.

\subsection{Specific Gravity \& Water Absorption test}

In general, Specific Gravity is actually the ratio of the weight of a given volume of aggregate to the weight of an equal volume of water. It is considered that at a temperature of $73.4^{\circ} \mathrm{F}\left(23^{\circ} \mathrm{C}\right)$, water has a specific gravity of 1 . Specific Gravity is important for several reasons as like some deleterious particles are lighter than the good aggregates and for tracking them specific gravity can be used because sometimes it indicates a change of material or possible contamination and the differences in specific gravity may be used during production to separate the deleterious particles from the good using a heavy media liquid. Where water absorption indicates the increase in weight of aggregate due to water in the pores of the material, but must check it is not including water adhering to the outside surface of the particles. [14] Water absorption gives value gives an idea on the internal structure of aggregate. Aggregates having more absorption are more porous in nature and less absorption value indicates less porous. According to AASHTO specification specific gravity and water absorption test was conducted both for CDW and CA which results are tabulated in Table 5.

Table 5. Specific Gravity \& Water Absorption Test value for CDW and CA

\begin{tabular}{ccccc}
\multirow{2}{*}{$\begin{array}{c}\text { Sample } \\
\text { Name }\end{array}$} & \multicolumn{2}{c}{ Specific Gravity } & \multicolumn{2}{c}{ Water Absorption (\%) } \\
\cline { 2 - 5 } & CDW & CA & CDW & CA \\
\hline Asw & 1.76 & 1.77 & 6.90 & 11.50 \\
Bsw & 1.73 & 1.75 & 7.56 & 12.40 \\
Csw & 1.75 & 1.76 & 8.40 & 12.80 \\
\hline \multirow{2}{*}{ Average } & 1.75 & 1.75 & 7.62 & 12.23 \\
\hline
\end{tabular}

Average value of specific gravity for CDW and CA are experienced almost same and water absorption value of CDW is $38 \%$ less than CA and both are less than $20 \%$ which indicates the better quality of aggregate.

\section{Conclusion}

Every year a huge amount of waste is generated due the construction and demolition of aging concrete structures, consequently increasing the environmental loads. Bangladesh, being a small country, resources like brick chips, stone chips etc. are limited and they incur significant cost in a construction project. If Construction and Demolition Waste (CDW) aggregate can be used safely in construction works, it will reduce the construction cost as well as minimize the problem of disposing the demolished materials. Therefore, it will bring economy in civil construction sector. This study was carried out to investigate the properties of CDW and compared with the properties of Conventional Aggregate. In case of CDW, AIV test value experienced $29.52 \%$ which satisfy the limit for using in road surfacing, ACV test value is $28.1 \%$ which is also satisfies the requirement to use in road pavement. Even in case of LA test (31.47\%), value is within the allowable limit. Using of CDW aggregate in pavement design which can minimize the requirement of conventional aggregate. The viability of CDW aggregate is almost same as Conventional Aggregate for using in road pavement for base $\&$ sub base layer.

\section{Recommendation for Future Work}

It is obviously that CDW analysis has better future but, in this research, only AIV, ACV, LA abrasion value, specific gravity and water absorption criteria are compared. In future it is recommended to observe the durability behavior under adverse weather, effect of temperature, vibration etc. It is also expected to research about construction and maintenance cost analysis at all.

\section{Declaration of Conflict of Interests}

The authors declare that there is no conflict of interest. They have no known competing financial interests or personal relationships that could have appeared to influence the work reported in this paper.

\section{References}

[1.] Sultana, A., Roknuzzaman, M., Afrose, A., and Dev, T. (2021). Impact of Multiple Recycling on the Strength of Coarse Aggregate, Civil Engineering Beyond Limits, 1,12-15.

[2.] Eurostat, 2014. Waste statistics in Europe. $<$ http://epp.eurostat.ec.europa.eu/> (July, 2014). 
[3.] Dosho, Y. (2007). Development of a sustainable concrete waste recycling system. Journal of Advanced Concrete Technology, 5(1), 2742.

[4.] Mahayuddin, S. A., Pereira, J. J., Badaruzzaman, W. H. W., and Mokhtar, M. B. (2008). Construction waste management in a developing country: case study of Ipoh, Malaysia. WIT Transactions on Ecology and the Environment, 109, 481-489.

[5.] Rodrigues, F., Carvalho, M. T., Evangelista, L., and De Brito, J. (2013). Physical-chemical and mineralogical characterization of fine aggregates from construction and demolition waste recycling plants. Journal of cleaner production, 52, 438-445.

[6.] Hansen, T. C. (Ed.). (1992). Recycling of demolished concrete and masonry. CRC Press.

[7.] Mohod, M. V., and Kadam, K. N. (2016). A comparative study on rigid and flexible pavement: a review. IOSR Journal of Mechanical and Civil Engineering, 13(3), 84-88.

[8.] Lambebo, B. A. Laboratory Based Evaluation of Aggregate from Hawassa Monopole Quarry in Southern Ethiopia: For use as Base Course of Road Pavement.

[9.] Vega A D.L., Santos J., and Martinez-Arguelles G. (2020). Life cycle assessment of hot mix asphalt with recycled concrete aggregates for road pavements construction. International Journal of Pavement Engineering, 16, 1-4.

[10.] BS 882: 1992, Specification for aggregate from natural resources for concrete. London: British Standards Institution; 1992.

[11.] Butler, L., West, J. S., and Tighe, S. L. (2013). Effect of recycled concrete coarse aggregate from multiple sources on the hardened properties of concrete with equivalent compressive strength. Construction and Building Materials, 47, 1292-1301.

[12.] IS2386-Part, I. I. I. (1963). Methods of test for aggregates for concrete. Bureau of Indian Standards, 11-4.

[13.] VicRoads. (2007). Standard Specifications for Road Works and Bridge Works. Section 820: Recycled Crushed Concrete for Pavement Sub-Base and Light Duty Base.

[14.] AASHTO, T. (2013). 84 "Standard Method of Test for Specific Gravity and Absorption of Fine Aggregate". American Association of State Highway and Transportation Officials, Washington, DC.

\section{How to Cite This Article}

Sultana, A., and Rahman, M.M., Suitability Assessment of Construction and Demolition Waste as a Highway Material, Brilliant Engineering, 1(2022), 1-5. https://doi.org/10.36937/ben.2022.4496 